\title{
A LIRA CHINESA EM TRÂNSITO: DE MACHADO DE AsSIS A ANTÓNIO FEIJÓ
}

\section{Marta Pacheco Pinto}

Resumo: Este ensaio é um trabalho em curso sobre a circulação e o diálogo transatlânticos de textos, autores e ideias que alimentaram o orientalismo literário em língua portuguesa. Centra-se especificamente nos movimentos interrelacionados que subjazem à coleção de poesia clássica chinesa em tradução francesa decimonônica, tal como Le Livre de jade, de Judith Gautier, e suas traduções para o português: a "Lyra chineza" de Machado de Assis inclusa em Phalenas (1870) e o Cancioneiro chinez de António Feijó (1890, 1903). Assim, o propósito principal é traçar um mapa dos contatos pessoais e transferências tradutórias que podem ajudar a entender melhor $\mathrm{o}$ fenômeno do orientalismo literário e o exotismo em língua portuguesa em quanto complexa rede de textos, autores e tendências estéticas.

Palavras-chave: Machado de Assis; António Feijó; "Lyra chineza”; Cancioneiro chinez; História da tradução; Orientalismo literário.

\begin{abstract}
This essay is a work in progress on the transatlantic circulation and dialogue of texts, authors and ideas that fuel literary orientalism in Portuguese language. It focuses specifically on the interrelated movements underlying a nineteenth-century collection of classical Chinese poetry in French translation, i.e. Judith Gautier's Le Livre de jade (1867), and its translations into Portuguese: Machado de Assis' "Lyra chineza” as included in Phalenas (1870) and António Feijó's Cancioneiro chinez (1890, 1903). The main purpose is thus to draw a map of cultural and personal contacts and translation transfers that may help better understand the phenomenon of literary orientalism and exoticism in Portuguese language as an intricate network of texts, authors and aesthetic tendencies.
\end{abstract}

Keywords: Machado de Assis; António Feijó; "Lyra chineza"; Cancioneiro chinez; Translation History; Literary Orientalism. 
discussão em torno da distinção entre traduzir, verter, adaptar ou
imitar - conceitos que convocam diferentes níveis de manipulação
de um texto de partida, sendo que a adaptação e a imitação caminham em direção à tradução livre - ganha novo fôlego em Portugal na segunda metade do século XIX, na sequência da polémica instalada em torno da tradução de Fausto (1872), de Goethe, por António Feliciano de Castilho. Na opinião de João Barrento, a "Questão do Fausto" é dos melhores exemplos dentro da tradição portuguesa de alienação do Outro (2002, p. 217), isto é, uma tradição de poetas que traduzem poetas ajustando-os "à sua própria experiência do mundo, da língua e da literatura” (BARRENTO, 2002, p. 216). Desconhecedor da língua alemã, Castilho sustenta que, para traduzir, não é imperativo conhecer a língua de partida (1997, p. 152) e, como exemplo, cita o amigo Machado de Assis pelos seus "lindos fragmentos de poesias orientaes tomadas não dos textos primitivos, senão de uma interpretação ingleza” (1997, p. 152).

Tendo em conta a data de redação do texto de Castilho (1872), esses "lindos fragmentos de poesias orientaes" não podem senão ser os oito poemas que dão vida à "Lyra chineza" machadiana, segunda secção de Phalenas (1870). Esses poemas não provêm, contudo, de um texto de partida inglês mas sim francês; trata-se de Le Livre de jade, uma coleção de poemas em prosa traduzidos do Chinês para Francês por Judith Gautier (1845-1917), poemas na sua maioria procedentes do período clássico da dinastia Tang (618-907) e também da Song (960-1279), e publicada sob o pseudónimo de Judith Walter pela editora Alphonse Lemerre, um mês após a Exposição Mundial de Paris, em 1867, que em muito contribuiu para a consolidação ou renovação do gosto europeu pelo exótico oriental. Esta mesma coleção seria mais tarde, duas décadas após o exercício machadiano, traduzida, na sua quase totalidade, para Português europeu pelo poeta minhoto António Feijó (1859-1917). Cancioneiro chinez (primeira edição em 1890; segunda edição em 1903), assim viria a chamar-se a recolha dos poemas que Feijó verteu e adaptou aos seus princípios estéticos, numa fase que a literatura crítica é unânime a descrever pela busca do rigor métrico e da precisão versificatória e a colocar em sintonia com as tendências finisseculares das principais literaturas europeias.

Neste ensaio, não é meu propósito comparar as traduções de Machado de Assis com os poemas de partida franceses - estudo, aliás, já realizado por Edgar Colby Knowlton Jr. (1995) -, menos ainda com os poemas que figuram em Cancioneiro chinez, mas antes refletir sobre a circulação transatlântica de textos, autores e ideias. Escrevendo da perspetiva do sistema literário de Portugal, pretendo sobretudo clarificar as circunstâncias por detrás da emergência de uma obra como Cancioneiro chinez em ligação ao exercício primeiro desencadeado por Machado de Assis. É meu propósito que este trabalho de reflexão constitua um ponto de partida para melhor compreender o fenómeno do orientalismo literário e do exotismo em língua portuguesa como rede dialógica e transatlântica de textos, autores e ideias.

II

Le Livre de jade dá à estampa em 1867 pela editora Alphonse Lemerre, a que ficaria ligada a escola parnasiana francesa. Entre 1866 e 1876, a editora publica, em três séries, a recolha Le Parnasse contemporain, cuja direção foi ocupada pelo poeta 
Catulle Mendès (1841-1909), com quem Judith Gautier contrai matrimónio em 1866, juntamente com Louis-Xavier de Ricard (1843-1911). Com efeito, a ligação de Judith ao credo parnasiano deve ser enquadrada no âmbito das suas relações familiares, quer com o seu pai Théophile Gautier, que seria aclamado como o pai do parnasianismo e o seu grupo de amigos, de que fizeram parte, entre outros, Gustave Flaubert, Charles Baudelaire e Victor Hugo -, quer com o marido Catulle Mendès, que dinamizou o debate parnasiano ao acolher na sua residência parisiense personalidades que ficariam associadas a Le Parnasse contemporain e, por conseguinte, à escola parnasiana: desde Théodore de Banville, Leconte de Lisle e François Coppée a Auguste Villiers de l'Isle-Adam, José-Maria de Heredia ou Paul Verlaine, entre outros (RICHARDSON, 1986, p. 29; PENHA, 1899, p. 57). Mais tarde, estas tertúlias passariam para as instalações da própria Alphonse Lemerre, que, já no final de 1865, assumira a impressão da revista L'Art de Louis-Xavier de Ricard. Apesar de uma existência efémera, é neste periódico que é formulada pela primeira vez a doutrina parnasiana (RICHARDSON, 1986, p. 39).

A boa receção de Le Livre de jade na segunda metade do século XIX está patente não apenas no número de edições que conhece (1902, 1908, 1928 e 1933 ${ }^{1}$ ), mas também nas inúmeras traduções, na sua maioria parciais, que gerou para outras línguas ocidentais, publicadas em forma de livro ou como parte de antologias literárias mais vastas, influenciando poetas e escritores um pouco por toda a Europa ${ }^{2}$. Assim se comprova, pelo número de reescritas gerado, que o êxito alcançado acabaria por permitir não apenas a consolidação de uma estética literária orientalizante no circuito literário europeu, mas também a criação, dentro desse circuito, de um espaço para a literatura chinesa por via da própria ideia de poesia clássica chinesa posta em circulação. Como constata Ferdinand Stocès, este tipo de obra viria a ter "une influence non négligeable sur la représentation que de nombreux Européens se sont fait de la poésie chinoise pendant des décennies” (2006, p. 350).

As primeiras traduções que se conhecem de poemas de Le Livre de jade surgem não na Europa mas no outro lado do Atlântico, no Brasil, pela mão de Machado de Assis. Em 1870, o poeta inclui, em Phalenas, oito poemas “imitados” de Le Livre de jade na secção intitulada “Lyra chineza” (ASSIS, [1870], p. 109-126). Na opinião de Manuel Bandeira, o lirismo deste segundo livro de versos que Machado publica "não se destaca da poesia do tempo senão por um certo comedimento sentimental, que era inato no homem” (1959, p. 4). Opinião semelhante era a de Luís Guimarães Júnior, amigo íntimo do poeta, que não hesitou em apresentar Phalenas como uma obra à parte no universo machadiano pela "ausencia do espirito patrio, [pel]a falta de inspiração caracteristica” (GUIMARÃES JÚNIOR, 1870, p. 2). As

\footnotetext{
${ }^{1} \mathrm{O}$ êxito desta recolha é tal que conhece quatro reedições, duas ainda em vida de Judith Gautier (1902 e 1908) e duas pouco depois da sua morte (1928 e 1933). Pode ainda assinalar-se uma edição mais recente: Judith Gautier (trad.). Le Livre de jade. Apresentação, notas e bibliografia de Yvan Daniel. Colecção La Salamandre. Paris: Imprimerie Nationale, 2004. Ressalvo que, apesar de a literatura crítica não questionar a existência da edição de 1908, em momento algum da pesquisa consegui localizar um exemplar com esta data de publicação, pelo que considero duvidosas as indicações encontradas a respeito dessa edição fantasma.

${ }^{2}$ Ver o quadro-síntese do impacto tradutório de Le Livre de jade - compreendido entre 1867, data da primeira edição, e 1933, data da quinta edição - que apresento em: Marta Pacheco Pinto. Cancioneiro chinez: the First Portuguese Anthology of Classical Chinese Poetry. In: Teresa Seruya, Lieven D’hulst, Alexandra Assis Rosa, Maria Lin Moniz (Org.). Translation in Anthologies and Collections (19th and 20th Centuries). Amesterdão e Filadélfia: John Benjamins, 2013. p. 57-74.
} 
traduções de "Lyra chineza” valer-lhe-iam um breve comentário alusivo ao exotismo que propalam: "Prendem a attenção aquellas idéas excentricas e de uma exquisita originalidade”, concluindo que Phalenas prima, em geral, pela técnica métrica sem fazer jus à originalidade do poeta (GUIMARÃES JÚNIOR, 1870, p. 2).

Jean-Michel Massa é perentório a estabelecer o cronista Artur de Oliveira (1851-1882) como intermediário na atração machadiana pelo Oriente exótico: “Assim, por intermédio de Arthur de Oliveira, ele [Machado] se abriu a um tipo de obra que certamente não lhe era familiar. Arthur de Oliveira possuía em sua biblioteca um certo número de livros do campo do Oriente e do Extremo-Oriente que foram dados a Machado de Assis pela viúva do falecido” (2001, p. 25-26). Teria sido esta personalidade a dar a "conhecer aos [seus] contemporâneos as novidades literárias [provenientes de Paris], vale dizer, o parnasianismo, difundindo Théophile Gautier, Leconte de Lisle, Théodore Banville, Sully-Prudhomme e outros” (ASSIS, 2008, p. 270, n. 11). Durante a sua estada em Paris, Artur de Oliveira teria mesmo mantido relações de amizade com Gautier e sua filha (SKÁLY e FELSEN, 2011). Quanto às imitações machadianas de Le Livre de jade, Jean-Michel Massa evoca um programa estético ou literatura engajada (1966, p. 78) e insere-as, mais concretamente, num exercício de estilo, numa tendência pré-parnasiana ou atração por um estilo novo (MASSA, 1970, p. 94, 92), movimentos estes que a crítica em Portugal sustentaria, grosso modo, para Cancioneiro chinez ${ }^{3}$. A escassez, em geral, de bibliografia crítica sobre Phalenas e a pouca visibilidade que ela teria na imprensa brasileira de então sublinham, em meu ver, a sua importância menor no conjunto da obra de Machado poeta. E as poucas ou nenhumas linhas dedicadas a "Lyra chineza" levam-me a encarar este projeto de exotismo como pontual, cujos ecos ou relações com um possível orientalismo literário brasileiro estão ainda por determinar.

Em Phalenas, Machado de Assis cuida em acompanhar a sua "Lyra chineza" da seguinte nota final: “Os poetas imitados n’esta collecção são todos contemporaneos. Encontrei-os no livro publicado em 1868 pela Sra. Judith Walter, distincta viajante que dizem conhecer profundamente a lingua chineza, e que traduzio em simples e corrente prosa” (ASSIS, [1870], p. 215). Esta nota é relevante pelas várias imprecisões que contém, e que passarei a expor de seguida, pondo a descoberto a desinformação ou, dito de outro modo, a fragilidade do conhecimento de Machado a respeito do exercício tradutório que realiza. A mais óbvia imprecisão é a data de publicação de Le Livre de jade, que, como se viu, dá à estampa em 1867. Este erro pode levar-nos a questionar o modo de acesso de Machado aos textos que afirma imitar. Do "Catálogo atualizado da Biblioteca de Machado de Assis", organizado por Glória Vianna (2001, p. 144-274), não consta cópia alguma de Le Livre de jade. Embora o empréstimo ou circulação de livros entre amigos fosse, na altura, uma prática comum, é plausível supor que Machado tivesse contactado com as versões francesas através da sua leitura em periódicos e não propriamente no livro de Judith Gautier, o que justificaria, de igual modo, a seleção de poemas que imita. Até à data não encontrei informação que sustentasse esta hipótese.

\footnotetext{
${ }^{3} \mathrm{O}$ apêndice de textos críticos incluído na secção final da edição de 1903 de Cancioneiro chinez ("O Cancioneiro e a critica” [FEIJÓ, 1903, p. 119-135]) é representativo das principais tendências a nível da receção da obra pela imprensa portuguesa de final do século XIX e princípios do de XX.
} 
As outras imprecisões dizem respeito à figura de Judith Walter/Judith Gautier e à datação dos poemas. Na altura uma jovem de $22 \operatorname{anos}^{4}$, Judith não foi, certamente, uma "distincta viajante". A escritora e tradutora francesa transpôs uma única vez as fronteiras europeias, apenas em 1914, aos 69 anos de idade, quando é convidada a visitar a Argélia. Judith tornar-se-ia conhecida pelo seu poder de evocação poética e pelo papel catalisador da imaginação na criação da sua ideia de Oriente, que teria compensado o seu desconhecimento do território asiático: "The vision of the East remained before her and within her: a vision which owed much to books and pictures and conversations, but more to her intense and loving imagination”; “'I [Judith] haven't visited the Far East [...]. What could I hope for that would be superior to the idea I had formed of it? I couldn't possibly risk being disenchanted!'” (RICHARDSON, 1986, p. 177, 225-226).

À exceção de Tin-Tun-Ling (1830-1886), o tutor chinês com quem Judith aprenderia, durante quatro anos, a língua de Confúcio e a quem dedica a primeira edição de Le Livre de jade, todos os outros poetas que Machado imita são clássicos, pertencendo ao período áureo da dinastia Tang; são eles: Han-Tiê (Wang Ji, c.585644); Su-Tchon (a literatura crítica não conseguiu até à data apurar a existência deste poeta); Tan-Jo-Su (Zhang Ruoxu ou Chang Jo-Hsü, c.660-c.720); Tchan-Tiú-Lin (Zhang Jiuling ou Chang Chiu-Ling, 678-740); Tchê-Tsi (Qian-Qi ou Ch’ien-Ch’i, c.722-c.780); Thu Fu (Du Fu ou Tu Fu, 712-770) ${ }^{5}$. Destes poetas, os poemas incluídos em "Lyra chineza” são (seguimos a ordem de apresentação na edição de 1870): "Coração triste fallando ao sol. (Imitado de Su-Tchon)"; "A folha do salgueiro. (Tchan-Tiú-Lin)”; “O poeta a rir. (Han-Tiê)”; “A uma mulher. (Tchê-Tsi)”; “O imperador. (Thu-Fu)"; "O leque. (De-Tan-Jo-Lu [sic])"; "As flôres e os pinheiros. (Tin-Tun-Sing $[s i c])$ ”; e "Reflexos. (Thu-Fu)". Os poemas que Machado imitou não são, como se vê, de poetas contemporâneos. O próprio aparato paratextual de Le Livre de jade é escasso em informação que contextualize os poemas ou os poetas e que pudesse, portanto, desfazer o equívoco de Machado.

A 11 de agosto de 1870, Júlio César Machado, mais generoso do que Luís Guimarães Júnior, elogia Phalenas e o génio machadiano no folhetim "Cartas lisbonenses" de Gazeta do povo, mais tarde reproduzido no periódico A América (março 1871) ${ }^{6}$, incorrendo, porém, no mesmo erro de datação que Machado: "O livro alegra se depois pela lyra chineza, traducções primorosas de uns poucos de contemporaneos que se chamam Su Tchon, Te han-Tiú-Lin, Han Tsé, Tché-Tsi, etc., que são os Mendes Leal, os João de Lemos, os Bulhão Pato, os Vidal, e Thomaz Ribeiro da China; composições humoristicas, risonhas, gallantes, lembrando Heine muitas vezes - no Imperador, sobretudo, ironia graciosissima” (1870, s.p.). Não deixam de ser significativos os paralelismos que este desconhecedor da literatura chinesa estabelece, de forma aparentemente informada, entre os poetas chineses

\footnotetext{
${ }^{4}$ Seguimos a data de nascimento (1845) inscrita na sua biografia oficial (RICHARDSON, 1986) e no dicionário sobre a família Gautier (NOBLET, 2003, p. 157). Noutras publicações, como a do Dictionnaire illustré des auteurs français (AA.VV., 1961, p. 160), aponta-se o ano de 1850 como data de nascimento da escritora.

${ }^{5}$ As diferentes formas de grafar os nomes dos poetas chineses explicam-se em virtude da inexistência, no século XIX, de um sistema uniforme de transcrição do Chinês.

6 “Outro foi Júlio César Machado, que logo em 1870 exaltou as Falenas, recebido certamente de José Feliciano de Castilho, que vivia no Rio, e a quem Machado mandou o seu primeiro romance” (SARAIVA, 2009, p. 66).
} 
clássicos e os poetas contemporâneos de língua portuguesa, que aqui são equiparados e elevados a um estatuto modelar.

Ao contrário de Machado, António Feijó estará ciente do contexto histórico em que os poemas de Le Livre de jade estão mergulhados. A sua erudição literária é confirmada pelo testemunho de terceiros. Na introdução a Songs of Li-Tai-Pè (1922), uma versão inglesa dos poemas de Li Bai (701-762) traduzidos em Cancioneiro chinez, Herbert Stabler reporta-se à dedicação e ao esforço do poeta, que conhecera pessoalmente na Suécia, em se familiarizar com a literatura e a cultura chinesas: "[D]uring the six years in which he was engaged on his book, he read greatly in French and Portuguese in connection with Chinese literature and made a careful study of the works of the Jesuit missionary fathers” (1922, p. 4). Também o amigo Luís de Magalhães menciona o "estudo profundo do assunto, do espírito do lirismo chinês" (FEIJÓ, 2004c, p. 329-330).

Publicado, primeiramente, pela Livraria Magalhães \& Moniz, Cancioneiro chinez foi a única obra de António Feijó a ser publicada duas vezes em vida, em 1890 e em 1903. Ambas as edições têm como texto de partida a versão de 1867 de Le Livre de jade.

António Joaquim de Castro Feijó cedo manifesta os seus dotes poéticos, sobretudo durante os tempos de estudante de Direito na Universidade de Coimbra (1877-1883). Volvidos três anos após cursar em Coimbra e várias tentativas frustradas de ingressar na advocacia, envereda pela carreira diplomática. Esta leva-o, de julho de 1886 a dezembro de 1889, ao Brasil e, de seguida, em janeiro de 1891, à Suécia; é em Estocolmo que fixa residência e permanece até ao final dos seus dias (junho de 1917). O Brasil, envolvendo algumas deslocações pela Argentina e pelo Paraguai, e a Suécia, com as constantes viagens a França (sobretudo Paris), Dinamarca, Alemanha (sobretudo Berlim), Noruega e Rússia, foram os principais circuitos geoculturais por onde o poeta se movimentou.

Quando em 1886 contacta pessoalmente com Machado de Assis ${ }^{7}$, já há muito que Feijó iniciara o seu projeto de tradução. A documentação epistolográfica não esclarece quando nem como o poeta português teve conhecimento de Le Livre de jade, nem mesmo as razões que o terão motivado a este exercício tradutório. Feijó parece traduzir pelo simples prazer de traduzir, a que acresce uma assumida necessidade de afirmação de estilo e de mestria versificatória. É em Lyricas e bucolicas (1876-1883), de 1884, que se verifica pela primeira vez a inclusão de uma cantiga chinesa - "Sobre o rio Thchú (do poeta chinez Thu-Fú)" (FEIJÓ, 2004b, p. 100) -, mais tarde inserta em Cancioneiro chinez (FEIJÓ, 1890, p. 53-54) ${ }^{8}$. Podemos, por isso, situar o início do projeto de tradução de Le Livre de jade em 1884, perfazendo assim o período de seis anos atrás mencionado por Stabler. Por uma questão de maior rigor, podemos mesmo determinar a primeira metade de 1883 como data-limite da composição dessa cantiga chinesa, pois, em carta datada de 17 de setembro de 1883, afirma António Feijó que “[o] meu livro [Lyricas e bucolicas] já

\footnotetext{
7 "Literatos por ora conheço apenas o Machado de Assis, que é um velho mulato extremamente simpático. Ele mesmo me tem confirmado a minha ideia - de que é insignificantíssimo o movimento literário do Império. Por cá, em poesia, os grandes homens são ainda Tomás Ribeiro e Bulhão Pato” (carta 28 julho 1886 - FEIJÓ, 2004a, p. 142).

${ }^{8}$ Este poema é uma proposta de tradução alternativa à imitação machadiana "Reflexos”, cujo poema de partida é "Sur le fleuve Tchou” (WALTER, 1867, p. 25-26).
} 
está no prelo” (2004a, p. 34) ${ }^{9}$. O projeto de tradução de Le Livre de jade é, por isso, anterior à colocação diplomática no Brasil.

Também o conhecimento da "Lyra chineza” machadiana é prévio ao contacto com Machado de Assis: "Já traduzi mais 4 chinesices. Parece-me, porém[,] que tudo o que no livro havia de mais belo já está esgotado. O Machado de Assis traduziu apenas 8, que lhe pareceram os mais notáveis. Eu já vou muito mais adiante" (carta 22 outubro 1885 - FEIJÓ, 2004a, p. 112-113). Do legado de António Feijó, atualmente disponível no Arquivo Municipal de Ponte de Lima, constam Chrysalidas (1864) e Poesias completas (1901) de Machado de Assis, mas não existem cópias de Phalenas, de Le Livre de jade ou mesmo de Le Dragon impérial (1869), romance por Judith Gautier, de onde o poeta-tradutor extrairia o poema "O Sacrificio de Gu-So-Gol", que viria a funcionar como coda da segunda edição de Cancioneiro chinês (FEIJÓ, 1903, p. 105-117). Pode então supor-se que o conhecimento da "Lyra chineza” machadiana advenha da sua publicação em antologias ou periódicos.

Por exemplo, a imitação machadiana "O leque” viria, em 1877, a ser incluída na recolha Parnaso portuguez moderno, por Teófilo Braga, com identificação da obra de onde é extraída e indicação do respetivo número de página. Assinado "Machado de Assis (Rio de Janeiro)", "Coração triste fallando ao sol (Imitado de Su-Tchon)" sai no periódico lisboeta Novo Almanach de lembranças luso-brazileiro para 1878 (1877, p. 366), sendo republicado em 1886, no número 17 d’A Imprensa. Revista scientifica, litteraria e artistica. Aqui a informação metatextual é mais vaga: "Coração triste fallando ao sol (versão do chinez)" ([ASSIS], 1886, p. 132). A 15 de outubro de 1884, o poema “Reflexos” é publicado n’O Archivo dramatico; esta tradução, identificada como "Lyra chineza - Reflexos (Thu-Fu)", não inclui, porém, qualquer referência metatextual a Machado de Assis (1884, p. 12), embora a comparação entre a versão aqui publicada e a versão de Phalenas não deixe margem para dúvidas sobre o facto de ser o mesmo texto.

O conhecimento de Le Livre de jade e da "Lyra chineza" machadiana pelo poeta Feijó poderá, então, ter sido suscitado ora pela leitura destas, e de outras, imitações poéticas dispersas, ora por influências procedentes diretamente de França. A primeira hipótese parece menos provável, dado que as imitações de Machado publicadas nos periódicos acima enumerados não se fazem acompanhar da identificação do texto de partida francês nem da obra machadiana de onde foram colhidas. Já a novidade que Le Livre de jade teria representado no panorama literário francês, ficando indelevelmente ligado ao parnasianismo francês e a um movimento de simpatia pelo Oriente, pode facilmente explicar o interesse de Feijó por esta obra. António Coimbra Martins assevera que, "[e]ntre romantismo e parnasianismo, a China apareceu várias vezes aos escritores franceses como estância ideal de arte, requinte, fantasia delicada e fino prazer [...] e teve a sua máxima expressão artística no famoso Livro de jade (1867), de Judith Gautier” (MARTINS, 1967, p. 151). A sua tradução, parcial ou total, mais ou menos livre, por Machado ou Feijó, pode ser assim entendida como um tributo ao gesto audaz de Judith Gautier e uma tentativa de inserção na modernidade literária europeia.

\footnotetext{
${ }^{9}$ A 24 de novembro de 1883, está já em processo de revisão de provas, conforme informa a Luís de Magalhães: "Só te podia incumbir da revisão de provas, mas esse trabalho, infelizmente, só pode ser feito por mim, em razão das grandes alterações que tenho necessidade de lhe introduzir.//Envio-te a 1 . $^{\mathrm{a}}$ parte da 1. " parte tal como deve sair a lume. Vê, dize-me o que pensas da edição e da obra” (FEIJÓ, 2004a, p. 39).
} 
Em síntese, até à data não consegui determinar quando se processou o conhecimento de "Lyra chineza" nem se foi o conhecimento dessas imitações que teria levado António Feijó a empreender o seu projeto de tradução, numa condenação do versilibrismo e como uma lição exemplificativa do que seria a forma perfeita em poesia: "As traduções dele [Machado de Assis] são todas em versos brancos, e por isso más, e até menos exactas que as minhas; a não ser as quadras 'Coração triste, falando ao sol' que ele imitou dum modo excepcionalmente belo" (carta 22 outubro 1885 - FEIJÓ, 2004b, p. 112-113). Embora Feijó venha a traduzir os mesmos poemas que Machado imitou, este excerto mostra, por um lado, que não baseou a sua tradução naquelas imitações, que condena pelo verso branco e pela ausência de rima - como, aliás, uma comparação entre as versões em Português evidenciaria -, conquanto se verifiquem contaminações lexicais e imagéticas. Apenas o título do poema "Coração triste, fallando ao Sol” - que em Cancioneiro chinez é atribuído a Thu-Fu quando na recolha francesa e na "Lyra chineza" está associado ao nome "Su-Tchon" - parece ser decalcado da versão machadiana, também ela "Coração triste fallando ao sol”, que é mais explícita do que o título francês, tão-só "Le Coeur triste au soleil” (WALTER, 1867, p. 73-74). Por outro lado, Feijó define a sua tarefa de tradução poética como uma de busca de exatidão, que, embora sem explicitar em relação a quê, se entende orientar no sentido da forma e da métrica. Essa tarefa tê-lo-ia levado a traduzir todos os poemas de Le Livre de jade, mas a organizar em volume apenas alguns.

Muitas das composições poéticas incluídas em Cancioneiro chinez foram primeiro publicadas, sobretudo entre 1885 e 1887, em periódicos nacionais, em particular no jornal portuense A Provincia, e em periódicos brasileiros, como o Diario de noticias (ver, por exemplo, as edições de 15 de março e 16 de maio de $1886^{10}$ ). É durante este período que o poeta se fixa no Brasil, a partir de 1886, primeiramente no Rio de Janeiro, a que se segue Rio Grande do Sul e Pernambuco, na qualidade de cônsul-adido à legação portuguesa. A 17 de junho de 1887, Feijó informa Luís de Magalhães de que concluíra as suas traduções poéticas:

Para dar a esta [carta] mais algum comprimento junto-lhe mais meia dúzia de cantigas chinesas para sobremesa da Província. Não sei se recebeste as outras nem como as achaste. A Musa por aqui não tem sugestões, e corre o perigo de morrer anémica. [...] Os chineses estão traduzidos - todos. Vou agora dar-me à pachorra de os reler e os corrigir, a ver se lhes consigo dar a máxima pureza e perfeição. Tenho-lhes muito amor porque me deram muito trabalho e quero ver se posso à força de paciência e tenacidade transformar em jóias alguns versos rudes e vulgares que por lá encontro. (FEIJÓ, 2004a, p. 170; ênfase nossa)

A informação desta carta é corroborada pelo dossiê manuscrito intitulado Cancioneiro chinez, que tem por subtítulo Livro de jade e faz parte da Coleção de Manuscritos, Datiloscritos e Impressos de António Feijón ${ }^{11}$, onde na folha que serve de

\footnotetext{
${ }^{10} \mathrm{Na}$ edição de 15 de março, na secção “Cancioneiro chinez”, incluem-se os poemas: “O Imperador (Thu-Fu)”, "Palacio no coração (Thu-Fu)” - que no livro é publicado com o título "Casa no coração” e "O Leque (Tan-Jo-Su)"; na edição de 16 de maio, na secção "Cancioneiro chinez", incluem-se os poemas: "O Cormoran (Su-Tong Pó); “As Pérolas de jade (Tchan-Tiu-Lin)”; “O Cão do vencedor (Thu-Fu)” e “A Flor de pessegueiro (Tsé Tsi)”.

${ }^{11}$ Agradeço ao Prof. Doutor J. Cândido Martins a cedência de cópias, em suporte digital, deste dossiê manuscrito, de onde foram extraídos os poemas que compõem a secção "Lira chinesa" do volume
} 
capa se encontram as indicações que se seguem a cor vermelha: "Publicado" e "18851887 R. G. do Sul”. Também a frase conclusiva no poema manuscrito "O Poeta sobe a montanha” determina o ano de 1887 como data de finalização da tradução: “Terminei a traducção do Livre de jade em 15 de Junho de 1887 - Rio Grande do Sul. Ant. ${ }^{\circ}$ Feijó". Embora os 21 poemas traduzidos que constam deste dossiê manuscrito não tenham sido incluídos em nenhuma das edições de Cancioneiro chinez, a indicação "Publicado" leva-nos a supor que aqueles poemas terão dado à estampa em periódicos da época. A julgar pela afirmação categórica de que os "chineses estão traduzidos - todos", a que acrescem os manuscritos encontrados, confirmamos que o poeta traduziu a coleção de Judith Gautier na íntegra, à exceção do último poema nela incluído, "Les Caractères éternels” (WALTER, 1867, p. 165-166), atribuído a Li Bai, o único para o qual não encontrámos qualquer prova documental de que tenha sido traduzido.

Nos três anos que se seguiram à conclusão dos “poemas chineses", entre o final de 1887 e 1890, coincidentes com um período de maior apatia e desânimo por causa das condições envolvidas na sua estadia no Brasil e das incertezas quanto ao seu futuro profissional ${ }^{12}$, o poeta teria sobretudo exercitado a sua técnica de aperfeiçoamento e depuração formais, que designa amiúde através da metáfora da “demão": "Por isso já dei a última demão aos poetas chineses, e aguardo apenas um momento de bom humor para organizar definitivamente um novo volume de versos que me não parecem de todo maus” (carta 23 maio 1888 - FEIJÓ, 2004a, p. 194). Teria sido o postulado estético da forma perfeita, que culminaria na máxima de que “un vers n'est jamais bien quand'il peut être mieux" (carta 31 julho 1890 - FEIJÓ, 2004a, p. 232) - que, como assinala Luís de Magalhães, seria uma variação do "preceito de mestre Theo [Gautier]: Ce qui n'est pas bien fait, n'est pas fait" (FEIJÓ, 2004c, p. 335) -, a ter determinado os poemas a integrarem Cancioneiro chinez.

Em 1903, a segunda edição de Cancioneiro chinês, que conta com um novo poema prefaciador e, no final, com um poema heroico de homenagem a Judith Gautier $^{13}$, tem uma saída significativa no Brasil em claro contraste com o que se verifica em Portugal ou sucedera com Phalenas. O fraco escoamento desta segunda edição em Portugal é indiciador do êxito, afinal, efémero da obra, que apenas no Brasil consegue atrair a atenção da crítica e do público-leitor: "O Cancioneiro tem tido no Brasil uma venda excepcional” (carta 24 novembro 1903 - FEIJÓ, 2004b, p. 87). Este facto pode explicar-se, por um lado, em virtude da diáspora chinesa que, desde o início do século XIX, estava a engrossar a população imigrante no Brasil. O próprio Eça de Queirós viria, em 1894, a alertar o país para os perigos dessa invasão: "Sereis inundados, submergidos. Virão cem, virão logo cem mil [...] e o Brasil todo, em vinte anos, será uma China [...] - metade da 'Gazeta de notícias' será impressa em chinês” (1997, p. 69-71). Por outro lado, pode ser indício de um revivalismo oriental

Poesias dispersas e inéditas (FEIJÓ, 2005), e que são designados como parte da Coleção de Manuscritos, Datiloscritos e Impressos, designação que aqui sigo.

12 “Abandonei os chineses e creio até que já não sei fazer versos. Em suma estou desesperado mas num desespero sombrio e triste” (carta 17 novembro 1887); "E tu que tens feito? Eu estou nesta profunda apatia em que te falei. Abandonei tudo, até os meus queridos chineses. Sinto-me sem forças nem coragem para coisa nenhuma” (carta 11 setembro 1888) (FEIJÓ, 2004a, p. 182, 203-204).

${ }^{13}$ Para além destes acréscimos, o poema "Sobre o rio marginado de flôres", atribuído ao poeta Tan-JoSu, é substituído pela composição "Na foz do rio" - identificada em Le Livre de jade como sendo de Li Bai enquanto Feijó a atribui a Tan-Jo-Su. 
no Brasil do início do século XX ou, pelo contrário, indício de que o gosto pelas chinoiseries chegaria mais tarde a Terras de Vera Cruz, onde a segunda edição de Cancioneiro chinez teria assim sido recebida como novidade que já não era em Portugal. A relação privilegiada do poeta com o Brasil valer-lhe-ia em 1915, dois anos antes de falecer, a eleição para sócio correspondente da Academia Brasileira de Letras. Em Portugal, e ao contrário das críticas abonatórias à primeira edição de Cancioneiro chinez, prevalece o silêncio da imprensa sobre a edição de 1903:

Na imprensa o silêncio tem sido absoluto, de forma que se eu tivesse de apreciar o mérito da obra pela recepção que lhe fizeram, não me restava outra coisa a fazer senão queimar os volumes que se não venderam. [...] O resto vende-se no Brasil, para onde foi, encomendada d'avance a maior parte da $2 .^{\text {a }}$ edição do Cancioneiro. (carta 7 julho 1903 - FEIJÓ, 2004b, p. 72)

Esta chinoiserie poética, não sendo mais novidade no mercado literário nacional, não teria conseguido captar a atenção de outrora. O mesmo fenómeno teria acontecido com a coleção poética Lin-Tchi-Fá. Poesias do Extremo Oriente (1925), de Maria Tamagnini (1900-1933), que estabelece claras afinidades intertextuais com Cancioneiro chinez. Basta comparar poemas como, por exemplo, "Amor e indiferença” (TAMAGNINI, 1991, p. 53-55) e "A uma mulher formosa” (FEIJÓ, 1890, p. 15-16) para verificar que essas afinidades estão muito próximas da reescrita. Segundo Natália Correia, esta coleção foi acolhida "com entusiasmos que em breve se esfumaram, dando lugar a um esquecimento que grosseiramente tem silenciado o nome da autora” (1991, p. 12). Os entusiasmos com que Cancioneiro chinez foi inicialmente abraçado teriam, todavia, como efeito adverso, o plágio de que António Feijó teria sido alvo no meio literário brasileiro e que Luís de Magalhães denuncia em "Plagiato litterario" $"$ :

Tenho aqui deante de mim uns poucos de jornais brasileiros: de S. Paulo, Pernambuco e Porto Alegre [...] onde encontro, sem nome do traductor e com o titulo de Poesias chinezas, algumas versões do Livro de jade [...]. E logo Antonio Feijó e o seu Cancioneiro chinez me veem á lembrança! [...]

Como se tratasse d'uma traducção, o bom do homem suppôz que, com algumas alterações da sua lavra [...] podia dar á sua obra um certo ar de originalidade. [...] [O] pobre homem ignorava de certo que as versões em verso de Feijó, sendo feitas atravez de versões em prosa, como a de Judith Gautier, não eram uma traducção litteral ou mesmo approximada, mas uma simples adaptação, onde o traductor se aproveitou apenas das idéas, dos conceitos e das imagens como de themas sobre que livremente modelou a sua forma, e que, assim, o metro, o rythmo, a structura estrophica d'essas versões não são originaes dos poetas chinezes, mas sim arbitrariamente escolhidos pelo poeta portuguez. [...] E lá se foi o sorridente plano: publicar a cousa assim, em fragmentos e anonymamente, nos jornaes - e mais tarde, se se não desse pela artimanha, zás, reunil-a em volume, oppondo-lhe então, já sem modestia, o glorioso nome... (MAGALHÃES, 1901, p. 379-380; ênfase do original)

\footnotetext{
${ }^{14}$ A obra em análise não é exemplo único de plágio por parte de letrados brasileiros. António Feijó pronuncia-se sobre os diversos casos de apropriação indevida dos seus poemas na correspondência privada, sobretudo em FEIJÓ, 2004a (ver também MARTINS, 2011, p. 124-128).
} 
Magalhães descreve aqui Cancioneiro chinez como uma "adaptação”, que define como a apropriação temática de um texto de partida a que o tradutor aplica uma forma livre dos constrangimentos formais de partida. O próprio poeta-tradutor assevera que os poemas "nunca foram traduções, eu servi-me apenas dos temas chineses, só dos temas - toda a forma, escolha de metro, divisão estrófica, etc., é meu, muito meu" (carta 19 dezembro 1900 - FEIJÓ, 2004a, p. 465; ênfase do original). O poeta-tradutor não hesita, como se vê, em declarar abertamente a assimilação do texto francês às suas preferências estéticas e estilo poético pessoais, assim confirmando a tradição portuguesa de alienação do Outro atrás evocada por Barrento (2002, p. 217).

As diferentes formas de circulação da lira chinesa de António Feijó (intertexto, reescrita ou plágio) sugerem que o impacto de uma obra de temática exótica seria proporcional à efemeridade da voga orientalizante a que estaria associada, ou seja, seria uma lógica da moda a determinar o êxito deste tipo de obra orientalizante, moda essa que, no final do século XIX e princípios do de XX, é moldada pelas tendências estéticas absorvidas a partir dos principais centros literários europeus, sobretudo Paris no caso luso-brasileiro.

A comédia jocosa Lei-San por Manuel Penteado (1874-1911), publicada pela editora Tavares Cardoso, a mesma que imprimiu a segunda edição de Cancioneiro chinês, surge, em meu ver, em reforço da lógica de uma moda da chinoiserie que parece estar ultrapassada no Portugal de início do século XX. Representada no Teatro D. Amélia a 31 de março de 1903, ano justamente da segunda edição da coleção de Feijó, as cenas iniciais, entre Lei-San e o amado Tai-Fo, são uma reescrita parodiante de poemas de Cancioneiro chinez, que por vezes relembram as cantigas de escárnio. Outro eco intertextual anterior que Cancioneiro chinez gerou, e que contribui para sublinhar a visibilidade da obra em contraste com o silêncio que envolve a "Lyra chineza" machadiana, é a recolha lírica Idyllios chinezes pelo poeta brasileiro Luís Guimarães, Filho (1876-1940), publicada em Lisboa em 1897. A mostra poética ("Navegando no Rio Amarello", "A lembrança da despedida" e "O pensamento da noiva") incluída no semanário Branco e negro, de 21 de fevereiro de 1897, ilustra bem a influência de Cancioneiro chinez: basta mencionar as referências cronotópicas e culturais gravadas nos poemas, as estratégias retórico-estilísticas (imagens, metáforas, comparações) que partilham entre si e remetem para lugares-comuns da cultura chinesa, bem como os temas glosados (ANÓNIMO, 1897, p. 335).

Ao contrário da lira chinesa que Machado de Assis inclui em Phalenas, António Feijó cumpre um projeto de maior dimensão e mais moroso, que se prolongaria de 1883 a 1903 e teria maior visibilidade na imprensa e na própria literatura então produzida, como os ecos intertextuais acima recolhidos testemunham.

\section{III}

Tendo em conta os dados reunidos, que podem vir a ser objeto de outras interpretações caso mais documentação seja dada à luz, impõe-se afirmar que a "Lyra chineza” de Machado de Assis, não obstante o seu impacto literário pouco expressivo, abriu um precedente em língua portuguesa que não pode ser obliterado. De igual modo os projetos de tradução analisados não podem deixar de ser considerados como fruto de iniciativas individuais, assim como de interesses e necessidades de experimentação estéticos similares. Seja como for, o interesse que o Oriente clássico chinês suscitou em António Feijó e a sua tentativa de compreensão dos preceitos 
estéticos chineses, podendo embora ter sido inspirados na lira machadiana, contribuíram para que Cancioneiro chinez ganhasse uma dinâmica e autonomia próprias no sistema literário português, ao ponto de ser tido por muitos como uma obra da autoria do próprio poeta. Por isso, identifico Cancioneiro chinez como um marco assinalável do orientalismo literário em língua portuguesa e um momento de viragem na história da tradução em Portugal e, claro, na história da tradução, ainda que mediada, do Chinês para Português. Embora a história da literatura portuguesa e da tradução em Portugal não lhe tenham sido favoráveis, Cancioneiro chinez veio despertar o sistema cultural português para a literatura chinesa em geral e a poesia chinesa em particular, a partir dele começando a raiar exercícios, diretos e indiretos, uns mais tímidos do que outros, de tradução literária do Chinês para Português. As oito "Elegias chinesas", da dinastia Ming (1368-1644), que Camilo Pessanha faz publicar a 13 de setembro de 1914 no jornal macaense O Progresso, serão uma das primeiras experiências de tradução direta de poesia chinesa para Português.

Em suma, a breve reflexão aqui exposta é apenas preliminar; com ela se espera abrir caminhos para que se possa começar a desenhar as redes de contacto intercultural que ajudaram a informar, na segunda metade do século XIX, o orientalismo literário e o imaginário poético extremo-oriental em Portugal, que, como se vê, é devedor da atração brasileira pelo exótico por via de Machado de Assis. Pretende esta reflexão chamar assim a atenção para o vasto caminho a trilhar do orientalismo literário em língua portuguesa e, se possível, despertar o interesse de quem nele queira aventurar-se.

Marta Pacheco Pinto

egma@sapo.pt

Centro de Estudos Comparatistas da Universidade de Lisboa

\section{Referências}

[ASSIS, Machado de, trad.]. Lyra chineza - Reflexos (Thu-Fu). O Archivo dramatico, Lisboa, n. 14, p. 12, 1884.

[ASSIS, Machado de, trad.]. Coração triste fallando ao sol (Imitado de Su-Tchon). A Imprensa. Revista scientifica, litteraria e artistica, Lisboa, n. 17, p. 132, jun. 1886.

AA.VV. Dictionnaire illustré des auteurs français. Paris: Seghers, 1961. 505p.

ANÓNIMO. 1897. "Idyllios chinezes" por Luiz Guimarães, Filho. Branco e negro: semanario illustrado, Lisboa, n. 47 (1. ${ }^{\circ}$ ano), p. 335, 21 fev. 1897.

ASSIS, Machado de. Coração triste fallando ao sol (Imitado de Su-Tchon). Novo almanach de lembranças luso-brazileiro para 1878, Lisboa, ano 7.․, p. 366, 1877.

ASSIS, Machado de. Correspondência de Machado de Assis. Tomo I - 1860-1869. Coordenação e orientação de Sergio Paulo Rouanet. Reunida, organizada e 
comentada por Irene Moutinho e Sílvia Eleutério. Rio de Janeiro: Academia Brasileira de Letras/Biblioteca Nacional, 2008. 334p.

ASSIS, Machado de. Phalenas. Rio de Janeiro: B. L. Garnier/Paris: E. Belhatte, [1870]. 219p. Disponível em <http://www.brasiliana.usp.br/bbd/handle/ 1918/00210100>. Acesso: 28 dez. 2011.

BANDEIRA, Manuel. O Poeta. In: Afrânio Coutinho (Org.). Obra completa, de Machado de Assis, vol. 3. Introdução geral de J. Galante de Sousa, Renard Pérez. Rio de Janeiro: José Aguilar, 1959. p. 3-6

BARRENTO, João. O Poço de Babel - para uma poética da tradução literária. Lisboa: Relógio d’Água, 2002. 273p.

CASTILHO, António Feliciano de. Advertencia. In: PAIS, Carlos Castilho. Teoria diacrónica da tradução portuguesa. Antologia (séc. $X V-X X$ ). Prefácio de Nuno Júdice. Lisboa: Universidade Aberta, 1997 [1872]. p. 148-154.

CORREIA, Natália. Versos de brisa portuguesa escritos numa flor de lótus. In: TAMAGNINI, Maria. Lin Tchi Fá - flor de lótus. Macau: Instituto Cultural de Macau, 1991. p. 9-12.

FEIJÓ, António. Cartas a Luís de Magalhães, vol. I. Apresentação, transcrição e notas de Rui Feijó. Posfácio de Luís de Magalhães. Lisboa: Imprensa Nacional-Casa da Moeda, 2004a. 509p.

FEIJÓ, António. Cartas a Luís de Magalhães, vol. II. Apresentação, transcrição e notas de Rui Feijó. Posfácio de Luís de Magalhães. Lisboa: Imprensa Nacional-Casa da Moeda, 2004b. 533p.

FEIJÓ, António. Poesias completas. Prefácio, fixação de texto de J. Cândido Martins. Porto: Edições Caixotim, 2004c. 484p.

FEIJÓ, António. Poesias dispersas e inéditas. Prefácio, fixação de texto e notas por J. Cândido Martins. Porto: Edições Caixotim, 2005. 281p.

FEIJÓ, António (trad.). Cancioneiro chinez. Porto: Magalhães \& Moniz Editores, 1890. 113p.

FEIJÓ, António (trad.). Cancioneiro chinês. Lisboa: Tavares Cardoso \& Irmão, 1903. 140p.

GUIMARÃES JÚNIOR, Luís. Estudos litterarios. Phalenas por Machado de Assis. Diario do Rio de Janeiro, Rio de Janeiro, 5 fev. 1870. Litteratura, p. 2-3.

KNOWLTON JR., Edgar Colby. Machado de Assis e a sua Lira chinesa. Revista de Cultura, Macau, n. 22 (série II), p. 81-93, 1995.

MACHADO, Júlio César. Folhetim - Cartas lisbonenses. Gazeta do povo, Lisboa, n. 246 (ano 2..$^{\circ}$ ), [s.p.], 11 ago. 1870.

MAGALHÃES, Luís de. Plagiato litterario. Brasil-Portugal, Lisboa, n. 48 (ano II), p. 379-380, 16 jan. 1901.

MAGALHÃES, Luís de. "Cancioneiro chinez" por Antonio Feijo. In: FEIJÓ, António. Sol de Inverno - ultimos versos (1915). Paris e Lisboa: Livrarias Aillaud e Bertrand, 1922. p. 211-214.

MARTINS, António Coimbra. Ensaios queirosianos - o mandarim assassinado, o incesto d' "Os Maias”, imitação capital. [S.l.]: Publicações Europa-América, 1967. 411p.

MARTINS, J. Cândido. Imagens de um poeta e cônsul diplomático: o Brasil visto por António Feijó. Limite, Cáceres, n. 5, 2001. p. 115-132. Disponível em $<$ http://www.revistalimite.es/volumen\%205/08candi.pdf> Acesso: 5 nov. de 2011. 
MASSA, Jean-Michel. A Biblioteca de Machado de Assis. In: José Luís Jobim (Org.). A Biblioteca de Machado de Assis. Teoria e História 2. Rio de Janeiro: Academia Brasileira de Letras, 2001. p. 21-90.

MASSA, Jean-Michel. Machado de Assis traducteur. Poitiers: [s.n.], 1970. 127p.

MASSA, Jean-Michel. Machado de Assis traducteur. Separata do vol. IV das atas do V Colóquio Internacional de Estudos Luso-Brasileiros. Coimbra: [s.n.], 1966. $11 \mathrm{p}$.

NOBLET, Agnès de. Un Univers d'artistes - autour de Théophile et de Judith Gautier. Dictionnaire. Prefácio de Jean-Philippe Bouilloud. Posfácio de Sylvie Camet. Paris: L’Harmattan, 2003. 548p.

PENHA, João. Por montes e valles (prosa). Lisboa: Livraria Editora Tavares Cardoso \& Irmão, 1899. 227p.

QUEIRÓS, Eça de. Chineses e japoneses. Lisboa: Cotovia, 1997. 71p.

RICHARDSON, Joanna. Judith Gautier: A Biography. Nova Iorque: Quartet Books, 1986. 312p.

SARAIVA, Arnaldo. Machado de Assis em Portugal. In: Vania Pinheiro Chaves, Lauro Moreira, Solange Aparecida Cardoso (Org.). Lembrar Machado de Assis 1908/2008. Lisboa: Centro de Literaturas de Expressão Portuguesa das Universidades de Lisboa Missão do Brasil junto à Comunidade dos Países de Língua Portuguesa, 2009. p. 62-70.

SKÁLY, Prachvoské, e Prachauer FELSEN. A Boêmia e os "boêmios” em Paris e no Rio de Janeiro. Théophile Gautier (1811-1872) e o "beau sauvage” Artur de Oliveira (1851-1882). Revista Brasil-Europa - Correspondência EuroBrasileira, n. 133 (5), 2001. Disponível em <http://www.revista.brasileuropa.eu/133/Indice_133.html> Acesso: 5 ago. 2013.

STABLER, Jordan Herbert. Introduction. In Songs of Li-Tai-Pè from the "Cancioneiro chines" of Antonio Castro Feijo. Nova Iorque: Edgar H. Wells \& Co., 1922. p. 1-6.

STOCÈS, Ferdinand. Sur les sources du Livre de jade de Judith Gautier (1845-1917) (remarques sur l'authenticité des poèmes). Revue de littérature comparée, Paris, n. 319, p. 335-350, jul./set. 2006.

TAMAGNINI, Maria. Lin Tchi Fá - flor de lótus. Macau: Instituto Cultural de Macau, 1991. 97p.

VIANNA, Glória. Catálogo atualizado da Biblioteca de Machado de Assis. In: José Luís Jobim (Org.). A Biblioteca de Machado de Assis. Teoria e História 2. Rio de Janeiro: Academia Brasileira de Letras, 2001. p. 144-274.

WALTER, Judith. Le Livre de jade. Paris: Alphonse Lemerre, 1867. 171p. 